\title{
SOIL DISCHARGING MECHANISM FOR SEAFLOOR DRILLING ROBOT
}

\author{
KEITA ISAKA, NAOAKI TADAMI, AMI FUJIWARA, \\ TOMOKI WATANABE, MANABU OKUI, AND TARO NAKAMURA \\ Faculty of Science and Engineering, Department of Precision Mechanics, \\ Chuo University, 1-13-27 Kasuga, Bunkyo-ku, Tokyo, 112-8551, Japan \\ E-mail:k_isaka@bio.mech.chuo-u.ac.jp \\ MAKOTO SUGESAWA, AND HIROSHI YOSHIDA \\ Japan Agency for Marine-Earth Science and Technology, Yokosuka, Kanagawa, Japan
}

\begin{abstract}
This work introduces a soil discharging mechanism that involves water jetting to further the development of a seafloor robotic explorer that can excavate and collect samples of rare earth elements. The excavation depth of previously reported drilling robots has been limited to $430 \mathrm{~mm}$; the discharging outlet became buried in the ground, making it difficult to discharge the drilled soil.
\end{abstract}

\section{Introduction}

The discovery of rare earth elements and other mineral resources on the sea floor has been found in the bottom of the ocean ${ }^{1}$. To utilize these resources, collection and analysis of samples must first be done to clarify how seabed mineral resources are generated and distributed. In a common sampling method, vertical drilling, shown on the left side of Figure 1, a pipe-shaped sampler is sent from the drillship to the seafloor to collect samples ${ }^{2}$. Although useful in acquiring a vertical geological profile, the sampling range of this method is limited to the diameter of the pipe (approximately $100 \mathrm{~mm}$ ) and thus is inefficient for investigating deposits widely distributed in the horizontal direction. To address this issue, this study aims to develop a robotic seafloor explorer that can excavate horizontally and collect samples. This would allow exploration over a wide area possible by deploying multiple robots to autonomously search beneath the seabed.

As such, several drilling robots have been proposed, such as PLUTO $^{3}$ and MMUM ${ }^{4}$. However, due to their susceptibility to earth pressure and inability to adequately discharge drilled soil, they could not excavate deep underground. To overcome these challenges, an underwater drilling robot, SEAVO II, was developed that was able to successfully drill $430 \mathrm{~mm}$ into the seabed ${ }^{5}$. Furthermore, drilling methods to reduce the drilling resistance have also been addressed ${ }^{6,7}$. Despite these improvements, SEAVO II could not excavate deeper than $430 \mathrm{~mm}$, as the discharging outlet of SEAVO II became buried in the ground and could not continue discharging the drilled soil. Therefore, this paper proposes a discharging mechanism that implements water jetting to allow for deeper seafloor excavation using SEAVO II.

The paper is organized as follows. SEAVO II is introduced and discussed in Section II. The concept of the discharging mechanism is then explained in Section III. Section IV clarifies the properties of the discharging mechanism. Conclusions and future work are presented in Section VI. 


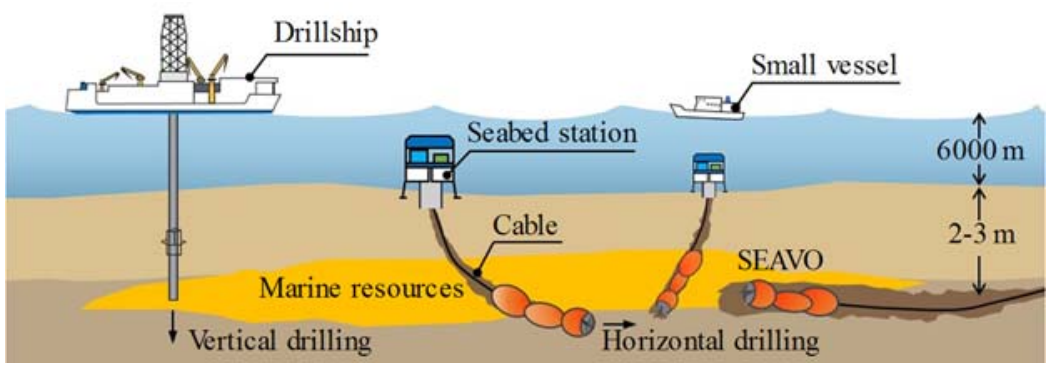

Figure 1. Vertical and horizontal drilling (concept of SEAVO)

\section{Drilling Robot SEAVO II}

\subsection{Components and locomotion method of SEAVO II}

SEAVO II was designed to consist of two units, an excavation unit and a propulsion unit, as shown in the conceptual model presented in Figure 2. The excavation unit excavates the ground and generates a space for locomotion. The propulsion unit moves by extending and contracting cylinders, similar to the movement of an earthworm; this locomotion method is demonstrated in Figure 3.

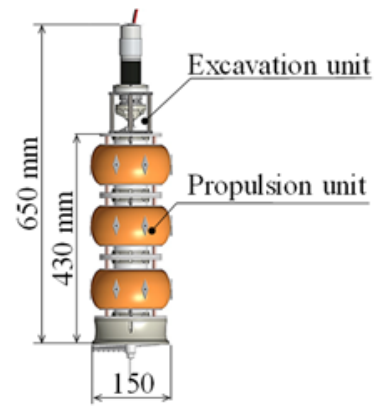

Figure 2. Conceptual model of SEAVO II

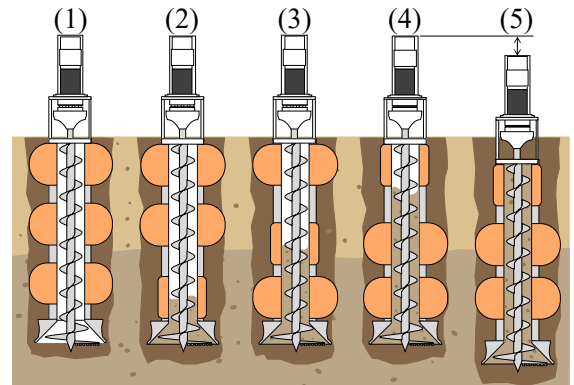

Figure 3. Locomotion method of SEAVO II

\subsection{Excavation and propulsion units}

The excavation unit consists of a motor (RS-775GM504, Suzakugiken), discharging outlet, casing pipe, earth auger, and head part, as shown in Figure 4. The internal structure of propulsion unit, shown in Figure 5, consists of setae ${ }^{5}$, plates, a casing pipe, guide shafts, a pneumatic cylinder (CJ2B16-15Z, SMC), and a rubber tube. Currently, pneumatic actuators are used, but hydraulic actuators should be implemented before any deep-sea applications.

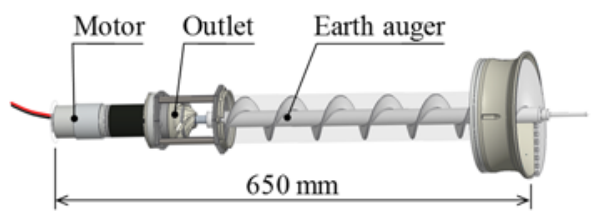

Figure 4. Excavation unit

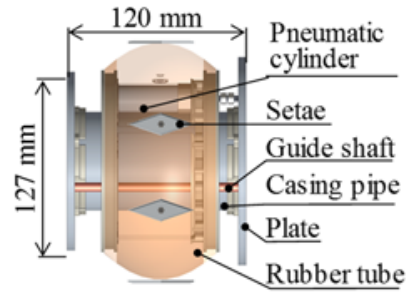

Figure 5. Propulsion unit 


\section{Discharging Mechanism Utilizing Water jetting}

\subsection{Problems of SEAVO II}

Prior studies have shown that SEAVO II cannot excavate more than $430 \mathrm{~mm}$ while underwater with SEAVO II because the discharging outlet gets buried and it thus becomes impossible to discharge the drilled soil (Figure 7(a)). To reach the target depth of $3 \mathrm{~m}$, a discharging mechanism that enables SEAVO II to remove the drilled soil is necessary.

\subsection{Discharging with riserless drilling}

A riserless drilling mechanism that injects drilling mud to remove debris from the borehole was first developed, as shown in Figure 6. In the drilling riser system, drilling mud is injected from the tip of the drill bit.

(1) Removing debris from the bottom.

(2) Reducing the friction between drill pipe and borehole.

(3) Cooling the bit and drill pipe.

(4) Preventing the collapse of the borehole.

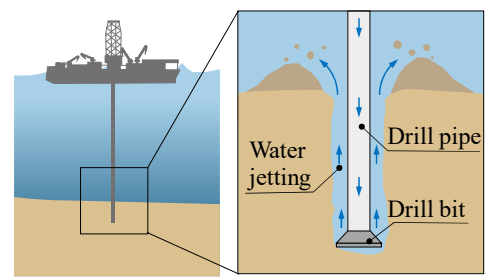

Figure 6. Riserless drilling system

\subsection{Discharging mechanism using water jetting}

A discharging mechanism imitating riserless drilling that uses water jetting was then implemented in SEAVO II. In this method, water is injected from the discharging outlet of SEAVO II during excavation, as shown in Figure 7(b). Here, the water enters between sand particles, fluidizing the ground. The fluidized sand is then transferred to the seabed surface by water flow, providing a smooth discharge of drilled soil and allowing SEAVO II to reach the target depth. The seawater necessary for water jetting is supplied from the seabed station.

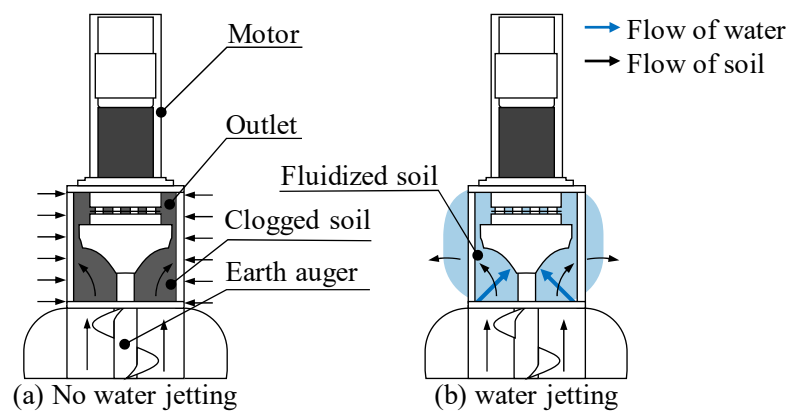

Figure 7. Discharging mechanism using water jetting 


\section{Properties of The Discharging Mechanism}

Two experiments were performed to clarify the flow rate and the drilling torque properties of the discharging mechanism.

\subsection{Experimental methodology}

Photographs and a cross-sectional schematic diagram of the discharging mechanism produced with a 3D printer are shown in Figure 8. The mechanism has four nozzles, each with a diameter of $1.5 \mathrm{~mm}$, positioned symmetrically and diagonally from each other. The experimental setup consisted of simulated ground, an excavation unit equipped with the discharging mechanism, a pore water pressure gauge (BPR-A-200 KPS, KYOWA), a feed pump, a regulator, a digital flow gauge (BEVEL BOX BB-180, Niigata Seiki), a water level sensor, and a drain pump, as shown in Figure 9. The excavation unit was fixed in the liner guide. The depth from the ground surface to the pore pressure gauge is set to $220 \mathrm{~mm}$. The pore water pressure gauge was attached to the discharging mechanism, as shown in Figure 9. The flow rate was adjusted from 0 to $1 \mathrm{~L} / \mathrm{min}$ in $0.05 \mathrm{~L} / \mathrm{min}$ steps using a digital flow gauge and regulator. The earth auger was rotated at 20 $\mathrm{rpm}^{7}$. The total stress was held constant using the water level sensor and drain pump to ensure a water level in the tank of $150 \mathrm{~mm}$.

To simulate the surface layer of the seafloor, Toyoura Sand (Toyoura Keiseki Kogyo) with a uniform particle size was used. The simulated ground was produced by first filling the tank with a certain amount of tap water before scattering small amounts of sand from the top to deposit sand $800 \mathrm{~mm}$ high in the $500 \mathrm{~mm}$ long, $500 \mathrm{~mm}$ wide, and $1000 \mathrm{~mm}$ high tank. In the water-saturated sediment, the volume of contained moisture corresponds to the pore volume of the deposit. Therefore, its porosity could be calculated from the pore volume, which is $40 \%$.

Comparing fluidization conditions at varying depths is difficult because pore water pressure depends on the depth. As such, the excess pore water pressure ratio $\Delta u / \sigma^{\prime}$, or the ratio between the excess pore water pressure $\Delta u$ and the effective stress $\sigma^{\prime}$, was used as an evaluation index of the fluidization and was calculated via Eq. (1),

$$
\frac{\Delta u}{\sigma^{\prime}}=\frac{u-u_{0}}{\sigma-u},
$$

where $u$ is the pore water pressure after fluidization, $u_{0}$ is the pore water pressure before fluidization, and $\sigma$ is the total stress. $\Delta u / \sigma^{\prime}$ is an evaluation index commonly used for the evaluation of the liquefaction phenomenon in civil engineering ${ }^{8}$.
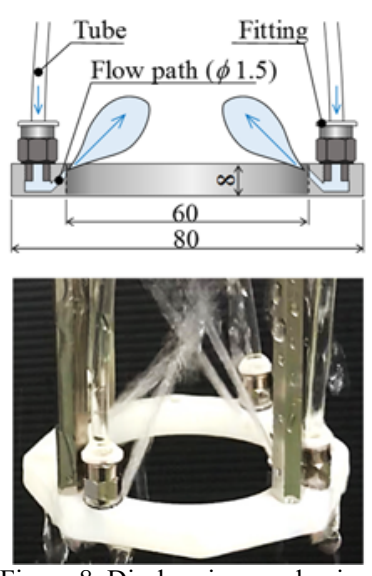

Figure 8. Discharging mechanism

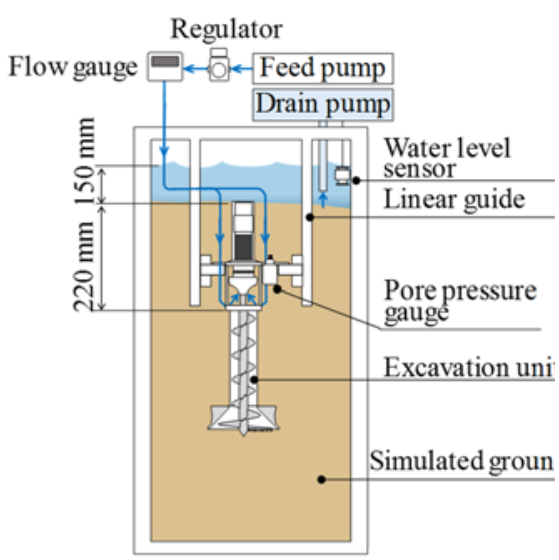

Figure 9. Experimental setup 


\subsection{Results of flow rate properties}

In Figure 10, the excess pore water pressure ratio $\Delta u / \sigma^{\prime}$ and pore water pressure are plotted against the floor rate. The pore water pressure increased with increasing flow rate, and the hardness of the ground decreased relatively. The pore water pressure was $3.4 \mathrm{kPa}$ at $0.0 \mathrm{~L} / \mathrm{min}$ and $3.7 \mathrm{kPa}$ at $0.05 \mathrm{~L} / \mathrm{min}$, indicating that the ground became fluidized by water jetting and thus confirming that water jetting is effective for ground fluidization.

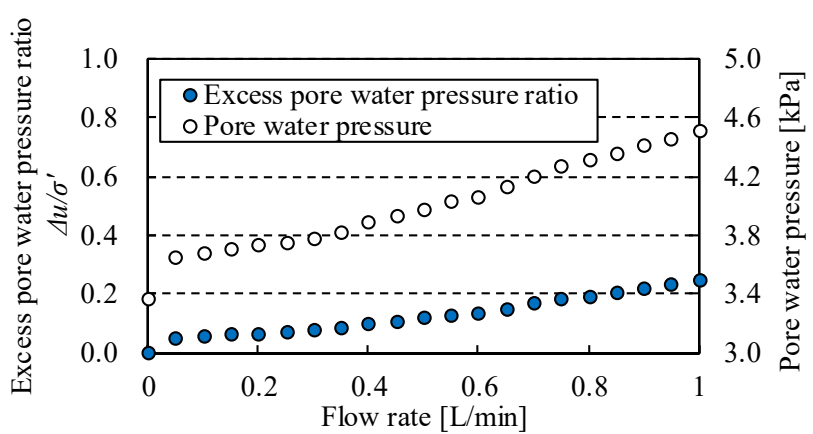

Figure 10. Results of the excess pore water pressure ratio and pore water pressure

\subsection{Results of drilling torque properties}

To determine the target value of the fluidization for adjusting the flow rate, we find the excess pore water pressure ratio when the drilling torque is lower than the allowable limit and when the flow rate is as small as possible. As a drilling torque above $11.6 \mathrm{~N} \mathrm{~m}$ was previously shown to cause SEAVO II to enter a "propulsion impossible" mode 5 , an allowable limit of torque was set to $11.6 \mathrm{~N} \mathrm{~m}$. The experimental method is the same as that in Section 4.1. We measure the drilling torque and the pore water pressure, and the experiment starts with the excavation unit being filled with drilled soil. In other words, discharging of the drilled soil begins immediately after the experimental start.

As shown in Figure 11, the drilling torque increased dramatically when no water jetting was used $(0.0 \mathrm{~L} / \mathrm{min}$ flow rate) and failed to excavate after $17 \mathrm{~s}$. Discharging the drilled soil was impossible, as the discharging outlet was already buried in the ground. A maximum drilling torque of $12.8 \mathrm{~N} \mathrm{~m}$ at $15 \mathrm{~s}$ exceeded the allowable limit. However, implementing water jetting reduced the drilling torque to below the allowable limit, enabling discharging of the drilled soil. The average drilling torque and excess pore water pressure ratio vs flow rate is shown in Figure 12. The average value of the drilling torque was calculated from $10 \mathrm{~s}$ after the steady state. At the lowest flow rate of $0.1 \mathrm{~L} / \mathrm{min}$, the average drilling torque was lower than the allowable limit of the torque and the excess pore water pressure ratio was 0.07 . An excess pore water pressure ratio greater than 0.07 around the discharging mechanism allows for the drilled soil to be discharged.

The discharging mechanism utilizing water jetting was able to generate a fluidized area and transport the drilled soil to the ground surface by water flow. The soil appeared to blow up from the ground surface. These results confirm the usefulness of the discharging mechanism utilizing water jetting. 


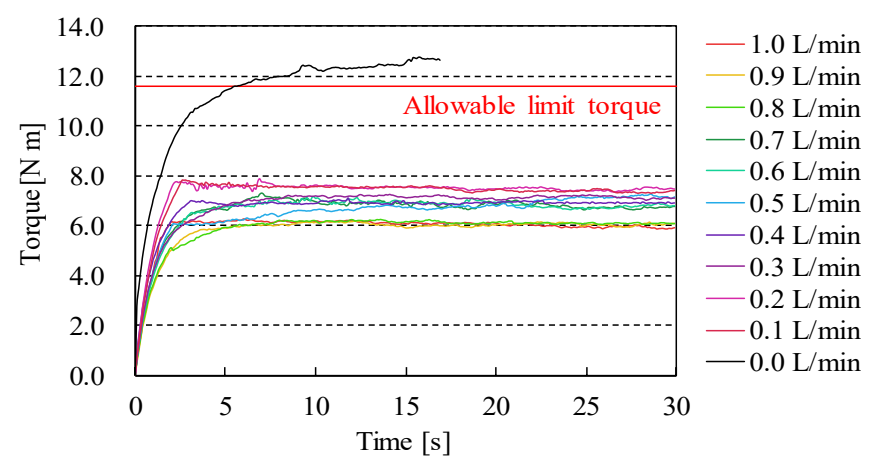

Figure 11. Drilling torque with and without water jetting over time.

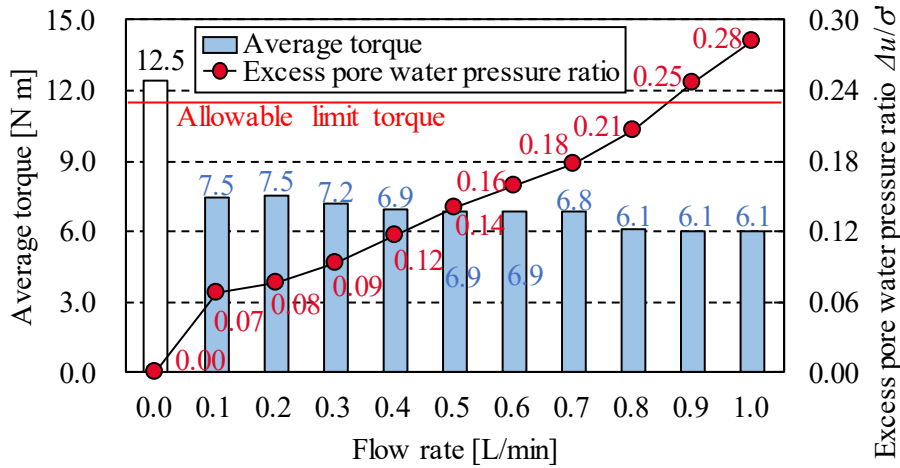

Figure 12. Average torque and excess pore water pressure ratio versus flow rate.

\section{Conclusions and future work}

In this paper, a discharging mechanism using water jetting was proposed and confirmed to be useful for fluidization and the smooth soil discharge from the characteristic experiments of the discharging mechanism. Future work will aim to understand the relationship between the depth and fluidization and consider whether it can be operated even several meters underground. Furthermore, the mechanism will be installed in SEAVO II to confirm the excavation performance of $430 \mathrm{~mm}$ or more.

\section{References}

1. S. Scott, "Marine Minerals: Their Occurrences, Exploration and Exploitation," OCEANS, 2011.

2. K. Wada, "Coring Technology to be applied in IODP NanTroSEIZE," OCEANS, 2008.

3. L. Richter, P. Coste, V. V Gromov and A. Grzesik, "The Mole with Sampling Mechanism (MSM) - Technology Development and Payload of Beagle 2 Mars Lander," Proc. of the 8th ESA Workshop on Advanced Space Technologies for Robotics and Automation, 2004.

4. C. R. Stoker, A. Gonzales and J. R. Zavaleta, "Moon/Mars Underground Mole," Proc. 2007 NASA Science Technology Conf. , 2007.

5. N.Tadami, K. Isaka, T. Nakatake, A. Fujiwara, Y. Yamada, T. Nakamura, M. Sugesawa and H. Yoshida, "Underwater Excavation by Excavation robot Equipped with Propulsion Unit Based on Earthworm Setae," Proc. IEEE Int. conf. on Robotics and Biomimetics, pp. 51-58, 2018. 
6. K. Isaka, N. Tadami, A. Fujiwara, T. Nakatake, Y. Yamada, T. Nakamura, M. Sugesawa and Y. Yoshida: "Water jetting Excavation and Consideration of Earth Auger Shape to Reduce Drilling Torque for Seabed Robotic Explorer," IEEE/ASME Int. Conf. on Advanced Intelligent Mechatronics, 2018.

7. K. Isaka, N. Tadami, A. Fujiwara, T. Watanabe, M. Sugesawa, Y. Yamada, Y. Yoshida and T. Nakamura "Study on Drilling Resistance Reduction of a Seafloor Robotic Explorer Based on the Drilling Properties of Underwater Ground," IEEE/SICE International Symposium on System Integration, 2019.

8. J. Wu, A. Kammerer, M. Riemer, R. Seed and J. Pestana, "Laboratory study of liquefaction triggering criteria," 13th World Conf. on Earthquake Engineering, 2004. 